\title{
СПЕЦИАЛЬНО-КРИМИНОЛОГИЧЕСКОЕ ПРЕДУПРЕЖДЕНИЕ ЖЕНСКОЙ ПРЕСТУПНОСТИ
}

\section{SPECIAL CRIMINOLOGICAL FEMALE CRIMINAL PREVENTION}

\section{T. Kononykhina}

Summary. The article considers the features of special criminological crime prevention among women in the Trans-Baikal region, Irkutsk territory and Buryat Republic. The author offers change measures of criminal motivation of female criminals as well as measures aimed at minimizing family conflicts. There are suggested countermeasures such criminal determinants of regional female crime as alcoholism and drug addiction. Attention focuses to the results of targeted programs operating within the framework of penal and postpenal prevention of female crime. The proposals presented in the article can be used to develop regional programs as well as to further improve the existing preventive measures by law enforcement agencies and public organizations in the area under consideration.

Keywords: female crime, female criminal identity, regional crime, special criminological crime prevention.

\author{
Кононыхина Татьяна Сергеевна \\ Преподаватель, Читинский институт (филиал) \\ Байкальского государственного университета \\ tskononykhina@mail.ru
}

Аннотация. В статье рассматриваются особенности специально-криминологического предупреждения преступности среди женщин в Забайкальском крае, Иркутской области и Республике Бурятия. Автором предлагаются меры по изменению преступной мотивации женщин-преступниц, а также меры, направленные на минимизацию внутрисемейных конфликтов. Предлагаются меры противодействия на такие криминогенные детерминанты региональной женской преступности как алкоголизм и наркомания. Обращается внимание на имеющие результаты целевых программ, действующих в рамках пенитенциарного и постпенитенциарного предупреждения женской преступности. Представленные в статье предложения могут быть использованы для разработки региональных программ, а также для дальнейшего совершенствования имеющихся предупредительных мер со стороны как правоохранительных органов, так и общественных организаций в рассматриваемой области.

Ключевые слова: женская преступность, личность женщины-преступницы, региональная преступность, специально-криминологическое предупреждение преступности.

витие существующего комплекса по противодействию преступности. В настоящей статье рассматриваются такие криминализированные регионы как, Забайкальский край, Иркутская область и Республика Бурятия, в структуре которых, женская преступность с каждым годом увеличивается.

Поскольку корыстная преступность в структуре региональной женской преступности превалирует и составляет около 50\% всех совершенных женщинами преступлений, основные усилия специально-криминологического предупреждения необходимо сосредоточить на предупреждении корыстных посягательств.

По мнению Е.В. Маковецкой наиболее эффективным средством для этого является широкое внедрение охранных систем, нанесение различных маркировочных знаков, таких как электронные штрих-коды, на имущество, которые позволяют пресечь попытки незаконного изъятия имущества и дают возможность идентификации его собственника [10; с. 111], что безусловно положительным образом скажется на преступности в целом, и женской преступности, в частности. Ровно, как и информирование посетителей общественных мест об ис- 
пользовании технических средств отслеживания за их действиями, так же поможет женщинам сдерживаться от преступного поведения при решении своих проблем.

Однако, представляется более важным в решении данного вопроса разработка мер по повышению уровня материальной обеспеченности, жилищных и бытовых условий малообеспеченных семей, входящих в группу риска. Разработка и реализация мер по обеспечению социальной занятости безработных, бездомных, ранее судимых и женщин, находящихся в кризисном и опасном для физического и душевного здоровья состоянии. Важным шагом к этому станет создание центра реабилитации для таких лиц, оказание им профессиональной консультативной помощи по медицинским, правовым и иным вопросам, а также психологической помощи, поскольку именно данная категория женщин, является возобновляемым ресурсом рецидивной преступности.

Так же существенную долю в структуре женской преступности занимают преступления против семьи и несовершеннолетних, что также требует особого внимания в части их предупреждения, а именно: мероприятия, направленные на выявление семей, отношения в которых носят конфликтный характер или характеризуются эмоциональной отчужденностью, с последующим обязательным социально-психологическим или медико-психиатрическим изучением и диагностированием агрессивно настроенных членов семьи. Результаты такого исследования должны быть положены в основу предупреждения внутрисемейных конфликтов. Столь же необходимой является консультативная помощь со стороны психологов, а затем и психиатров, если есть основания полагать, что кто-либо из участников отношений в микрогруппе страдает расстройством психики [13; с. 144]. Однако главная проблема здесь состоит в том, что ненадлежащие отношения в семье с трудом поддаются внешнему социальному контролю, поскольку явления, которые могут привести к совершению преступлений, зачастую порождаются скрытыми личными отношениями в семье, обнаружение которых связано с вмешательством в частную жизнь.

Следует обратить внимание на неблагополучные семьи, в которых есть дети. Зачастую подростки при ненадлежащих отношениях в семье бегут из дома и бродяжничают, начинают употреблять спиртные напитки, проявляют половую распущенность, начинают совершать противоправные поступки: кражи, хулиганские действия и др. Девушки реагируют на неблагоприятные условия жизни в семье более активно, чем юноши. Поэтому антиобщественное поведение почти всегда служит верным показателем семейного неблагополучия и указанием на необходимость срочного вмешательства.
Таким образом, основными мерами здесь может стать сотрудничество между правоохранительными органами и социальными службами на предмет обследования и диагностики семей, в которых сложились конфликтные семейные отношения и ситуации, повлекшие совершение в ней насилия; расширение сети кризисных центров, социально-реабилитационных центров для женщин, которые оказывают последним непосредственную помощь, а также реализуют программы коррекции семейных отношений [4; с. 157]; использование технологии восстановительного правосудия на уровне общественных организаций, занимающихся выявлением возможности примирения в конкретной семье, когда главной задачей выступает не поиск виновного и его жестокое наказание и не оправдание жертвы, а определение динамики отношений между партнерами, установление вины каждого члена семьи и совместная выработка плана прерывания цикла насилия [9; с. 113].

Учитывая специфику криминогенных детерминант в рассматриваемых регионах к профилактическим мерам специально-криминологического предупреждения женской преступности относится разработка специальных программ, направленных на борьбу с алкоголизмом и наркоманией. Обозначая синдром зависимости от алкоголя как проблему, которая может предрасположить лицо к совершению правонарушений, возникающих еще до рождения человека, приоритетное значение здесь приобретает алкоголизм родителей, так как у алкоголиков часто рождаются дети с органическим поражением головного мозга, нарушениями центральной нервной и эндокринной системы, которые существенно сказываются на развитии психики в целом.

Следует отметить, что на протяжении целого ряда лет стабильно высокие показатели первичной заболеваемости хроническим алкоголизмом отмечаются на территории северной части Иркутской области и некоторых центральных районов. В 2014 году на этих территориях значения показателя впервые выявленных случаев хронического алкоголизма превышали среднеобластной показатель в 2,0-11,8 раза. Всё это указывает на наличие северного градиента (вектора) заболеваемости [8; с. 78]. На территории Забайкальского края отмечается тенденция к снижению заболеваемости алкоголизмом, хотя в целом показатели остаются выше российских [5; с. 5].

Наименьшие значения показателя распространённости алкоголизма (ниже среднероссийского уровня) наблюдается в Республике Бурятия, где уровень распространённости больных алкоголизмом почти в два раза меньше, чем в Иркутской области и Забайкальском крае. Возможно, это связано с проводимыми в Республике Бурятия в 2017 году мероприятиями по совершенствова- 
нию системы оказания медицинской помощи наркологическим больным, которая позволила снизить уровень распространенности наркологическими расстройствами до 1264,7 на 100 тыс. нас. (- 3\%) [2].

Рассматривая заболеваемость синдромом зависимости от наркотических веществ на рассматриваемых территориях, отметим что он ниже общероссийского, однако, в силу своей вредоносности как на самих больных, так и на их будущем потомстве - это вопрос, не требующий отлагательств. В связи с этим профилактика алкоголизма и наркомании является важнейшим условием сверхраннего предупреждения преступлений лиц с патопсихологическими особенностями.

В целях реализации «Концепции государственной политики по снижению масштабов злоупотребления алкогольной продукцией и профилактике алкоголизма среди населения Российской Федерации на период до 2020 г.» был принят ряд нормативных правовых актов, целевых программ, направленных на профилактику социально-негативные явлений, в том числе подпрограмма «Комплексные меры профилактики злоупотребления наркотическими средствами и психотропными веществами» на 2014-2018 годы Государственной программы Иркутской области «Молодежная политика» на 2014-2018 годы; а также Постановления Правительства Иркутской области, которое, так же как и в Забайкальском крае устанавливает ограничения в сфере розничной продажи алкогольной продукции на территории Иркутской области.

Среди предупредительных мер можно отметить деятельность Координационного Совета по взаимодействию между государственными и негосударственными структурами Забайкальского края, занимающимися профилактикой алкоголизации и наркопотребления, реабилитацией лиц, страдающих зависимостью. Социальная, социально-психологическая и социально-трудовая реабилитация зависимых осуществляется в Центре психолого-педагогической помощи населению «Доверие», отделении социально-трудовой реабилитации «Солнышко» и др.

Положительным является опыт взаимодействия Медицинского отдела УФСИН РФ по Забайкальскому краю и Краевого наркологического диспансера, куда поступает информация о лицах, освободившихся из мест лишения свободы, страдающих наркологической патологией. Данная информация в десятидневный срок передается в государственные учреждения здравоохранения районов Забайкальского края, где обеспечивается своевременная постановка на учет и организация динамического наблюдения за указанными лицами, а также оказание медицинской наркологической помощи.
В целях профилактики наркологических заболеваний и формирования здорового образа жизни в Республике Бурятия среди несовершеннолетних и молодежи в 2017 году организованы лекционные занятия и социально-психологические тренинги в образовательных учреждениях, реабилитационных центрах, центрах дополнительного образования и центрах детского творчества; ежегодная акция «Велопробег против наркотиков», приуроченная к Международному дню борьбы с наркоманией и незаконным оборотом наркотиков. Также начаты профилактические медицинские осмотры обучающихся в целях раннего выявления незаконного потребления наркотических средств и психотропных веществ, антинаркотическая акция «Призывник» в Республиканском сборном пункте. В рамках акции «Армия против наркотиков» проведены лекции «Профилактика наркомании» в войсковых частях Улан-Удэнского гарнизона (охватом более 1000 человек). Кроме этого, ведется постоянная работа по информированию населения на профилактическом мультимедийном сайте «Элуур».

Особую значимость меры специально-криминологического предупреждения женской преступности приобретают при их проведении на индивидуальном уровне. Непосредственными объектами индивидуального предупреждения могут быть как конкретные лица, являющиеся носителями антиобщественной направленности и криминогенной мотивации.

При этом, криминальная мотивация отличается от мотивации социально-одобряемой деятельности целым рядом криминологически значимых особенностей, которые заключены в специфическом влиянии социальной среды и в содержании мотивационной сферы личности. Таким образом, для недопущения или приостановления формирования криминальной мотивации, профилактические меры должны быть направлены: во-первых, на устранение или нейтрализацию криминогенных факторов, способствующих ее формированию; во-вторых, на позитивное изменение (корректировку) мотивационной сферы профилактируемого лица [13; c. 140].

Следует помнить, что женщины в большей степени, чем мужчины подвержены внушению и убеждению, что обусловлено психологическими особенностями личности. В этой связи, для корректировки мотивационной сферы личности необходимо шире применять психологические основы превенции.

Так, например, в работе с женщинами, мотивация преступного поведения которых имеет корыстную направленность, психологические основы превенции должны быть направлены в первую очередь на формирование позитивной потребительской психологии, такое воздей- 
ствие должно раскрывать всю низменность стремлений к обогащению, накоплению имущественных благ. Противопоставление преступного поведения, моральным принципам, признаваемых лицом, а также сопоставление его собственных поступков с противоправными действиями других лиц должны убедить профилактируемого в необходимости достижения материального благополучия социально одобряемыми способами.

Пенитенциарная профилактика преступлений на индивидуальном уровне осуществляется в отношении женщин, чьи криминогенные деформации уже реализованы в совершении конкретных преступлений, в целях предупреждения рецидива. Реализуется она органами, исполняющими уголовное наказание. Такая профилактика направлена на изменение личностной криминальной установки осужденной за убийство женщины в сторону ее минимизации, на определение положительных жизненных перспектив после выхода на свободу, привитие позитивной направленности посредством исполнения мер правового принуждения [7; с. 285].

Постпенитенциарная профилактика заключается в ресоциализации личности после отбытия ею наказания, включающей устранение и нейтрализацию негативных условий пенитенциарного и постпенитенциарного характера. Ее целью является создание необходимых условий для успешной адаптации к жизни на свободе, посредством оказания ей помощи в социально-бытовом и трудовом устройстве, при возможном налаживании отношений с бывшими членами семьи и родственниками.

В региональном аспекте отметим долгосрочную целевую программу в Забайкальском крае «Социальная реабилитация и адаптация лиц, освободившихся из мест лишения свободы (2011-2014 годы)», целью которой стала реализация государственной политики в организации системы административных, социально-экономических, медицинских и психологических мероприятий, направленных на восстановление социального статуса освободившихся лиц и их способности к неконфликтной жизнедеятельности в социальной среде. В рамках программы в крае осуществлялось оказание лицам, готовящимся к освобождению из мест лишения свободы, профориентационных услуг; профессиональное обучение осужденных специальностям, востребованным на рынке труда; оформление паспортов заключенным до их освобождения; решение вопросов о временном или постоянном месте проживания осужденного после отбытия наказания. Одним из приоритетных направлений стало создание общественных формирований при органах местного самоуправления, осуществляющих функции по социальной адаптации освободившихся лиц и осужденных без изоляции от общества [11].
Нельзя не упомянуть об экспериментальном проекте «Женщина, уверенная в себе», запущенном ГУФСИН России по Иркутской области на 2016-2020 гг. в исправительных колониях региона, предназначенных для содержания осужденных женщин. Проект создан с целью содействия социальной адаптации осужденных женщин - как во время отбывания наказания, так и после освобождения. При этом, оказывается, как адресная помощь осужденным в восстановлении утраченных связей с родственниками, так и решаются вопросы трудоустройства и поиска жилья после освобождения, так и информационная и психологическая поддержка. Исправительные учреждения активно взаимодействуют с органами местного самоуправления, опеки и попечительства, центрами реабилитации наркозависимых, представителями различных благотворительных фондов [12].

Управлением Федеральной службы исполнения наказаний по Республике Бурятия и Общественной наблюдательной комиссией региона при поддержке некоммерческой организации «Межрегиональный благотворительный фонд помощи заключенным» при исправительной колонии № 7 в 2018 году был открыт реабилитационный центр «Аврора», цель которого состоит в обеспечении эффективной ресоциализации осужденных к условиям жизни в современном обществе, на основе применения индивидуальных и групповых форм воздействия, формирования уважительного отношения к человеку, обществу, труду, нормам, правилам и традициям общежития и стимулирования правопослушного поведения в соответствии с требованиями уголовно-исполнительного законодательства РФ. Это отдельное помещение, предназначенное для проживания осужденных, готовящихся к освобождению, численностью до 50 человек. Там будут находиться осужденные женщины, которым до освобождения осталось 6 месяцев, с положительной характеристикой, добросовестным отношением к труду, активно участвующие в воспитательных и культурно-массовых мероприятиях [3].

По нашему мнению, многим женщинам, отбывающим наказание, а также вернувшимся из мест лишения свободы, в формировании социальной идентичности, может помочь переосмысление религиозных традиций и обычаев. Главное назначение церкви состоит в воспитании высокой духовности женщин, их нравственном совершенствовании, надлежащего отношения к высшим человеческим ценностям, долгу перед семьей, детьми, обществом. О положительном воздействии религии на преступниц говорит и зарубежный опыт по предупреждению преступности и женской, в частности, в Швеции, Норвегии, Финляндии и Канаде, где христианские служители религии играют существенную роль не только в деле профилактики женской преступности, но и преступности вообще. Не случайно в названных 
странах женская преступность имеет один из самых низких в мире показателей [6; с. 147].

В учреждениях ФСИН России на сегодняшний день функционируют 523 храма, из них: 471 Русской православной церкви (РПЦ), 40 исламских мечетей, 9 буддийских дуганов и 3 костела Римско-католической церкви (РКЦ). Действует 705 молитвенных комнат, из них: $466-$ РПЦ, 115 - исламских, 6 - буддийских, 1 - иудейская, 2 - РКЦ, 64 - евангельских христиан-баптистов, 49 христиан веры евангельской (пятидесятников) и 3 - для представителей других вероисповеданий [1].

В настоящее время на территории исследуемых регионов действует Соглашения о сотрудничестве между Федеральной службой исполнения наказаний России и Русской Православной Церковью, благодаря которому осуществляется взаимодействие между епархиями Забайкальской, Иркутской, Бурятской и УФСИН России. В числе предусмотренных соглашением мер следует отметить создание условий для формирования у осужденных уважительного отношения к человеку, обществу, труду, нормам, правилам и традициям человеческого общежития, стремления к исправлению имеющихся негативных качеств, повышения образовательного и культурного уровня, стимулирования правопослушного поведения, а также помощь в трудовом и бытовом устройстве после окончания срока наказания [14].

Содействовать ресоциализации осужденных призвана и обязанность трудиться. Согласно ст. 103 УИК РФ каждый осужденный к лишению свободы обязан трудиться в местах и на работах, определяемых администрацией исправительных учреждений, с учетом их пола, возраста, трудоспособности, состояния здоровья, специальности, а также исходя из наличия рабочих мест [15]. Цель данной нормы состоит не столько в компенсировании затрат государства, связанных с содержанием осужденных, сколь- ко в содействии их исправлению. Так, в исправительных учреждениях исследуемых регионов осужденные женщины заняты трудовой деятельностью по специальностям «Швея» и «Мастер растениеводства». В том случае, когда трудоустройство осужденных невозможно по объективным причинам, то отсутствие трудовой деятельности можно заменить образовательным процессом. Так же осуществляется сотрудничество с образовательными учреждения по программам дистанционного обучения, например, в Забайкальском крае это взаимодействие с Забайкальским институтом предпринимательства Сибирского университета потребительской кооперации по направлениям: «Товароведение и экспертиза производственных товаров», «Прикладная информатика», «Бухгалтерский учет, анализ и аудит» и др.

Отмеченные мероприятия в экономической, социальной, семейной сферах требуют надлежащего информационного и пропагандистского сопровождения. Наиболее значимыми направлениями просветительской и информационной политики в деле профилактики женской преступности являются: распространение правовых знаний и формирование культуры правомерного поведения; утверждение в общественном сознании идеи гендерного равенства и недопущение дискриминации на основании полового признак; формирование нетерпимости к преступным проявлениям и недопущение смакования криминальных подробностей в средствах массовой информации.

Таким образом, эффективность специально-криминологического предупреждения преступлений, совершаемых женщинами, во многом зависит от действенности субъектов предупреждения преступлений. Однако рассмотренные выше меры должны применяться в их совокупности, взаимно дополняя друг друга, и в той мере, в какой это необходимо для получения лучшего результата.

\section{ЛИТЕРАТУРА}

1. Взаимодействие учреждений и органов УФСИН с судом и иными правоохранительными органами, средствами массовой информации, религиозными конфессиями и общественными объединениями [Электронный ресурс] URL: http://www.75.fsin.su/obshchestvennyy-sovet-pri-ufsin/ (дата обращения: 12.08.2017 г.)

2. Годовой отчет о результатах реализации основных мероприятий подпрограмм Государственной программы Республики Бурятия «Развитие здравоохранения», достигнутых в 2017 году [Электронный ресурс] URL: http://webcache.googleusercontent.com/search?q=cache: yl6Wqs4-P8wJ: www.minzdravrb.ru/ mals/26.03/ (дата обращения: 25.08.2017 г.)

3. День открытых дверей прошел в реабилитационном центре «Аврора» при исправительной колонии № 7 [Электронный pecypc] URL: http://03.fsin.su/ news/detail.php? ELEMENT_ID=408908 (дата обращения: 12.08 .2017 г.)

4. Елфимова Е. И. Правовые проблемы борьбы с домашним насилием // Вестн. Волгогр. гос. ун-та. Сер. 5, Юриспруд. 2013. № 2 (19). С. 154-159.

5. Заболеваемость хроническим алкоголизмом, алкогольными психозами и наркоманией в Забайкальском крае за 2010-2012 годы Чита: информационный сборник. Чита: Пресс-центр, 2013. 23 с.

6. Криминология: учеб. для вузов / под ред. В. Д. Малкова. М.: Юстицинформ, 2011.544 с.

7. Криминология: учебник / под ред. В. Н. Кудрявцева, В. Е. Эминова. М.: Норма: ИНФР-М, 2014.800 с. 
8. Лещенко Я. А., Боева А. В. Заболеваемость и смертность населения Восточной Сибири в связи с употреблением алкоголя // Международный журнал прикладных и фундаментальных исследований. 2016. № 3. С. 77-82.

9. Лысова А. В. Насилие в семье — объект социальной политики в (ША // Социологические исследования. 2005. № 12. С. $108-116$.

10. Маковецкая Е. В. Предупреждение женской преступности (по материалам Южного Федерального округа): дисс. ... канд. юрид. Наук: 12.00.08. Волгоград, 2015. $220 \mathrm{c}$.

11. 06 утверждении краевой долгосрочной целевой программы «Социальная реабилитация и адаптация лиц, освободившихся из мест лишения свободы (2011-2014 годы)»: Постановление Правительства Забайкальского края от 29 июня 2010 года № 275 [Электронный ресурс] // Кодекс: электронный фонд правовой и нормативно-технической документации, утратил силу (дата обращения: 12.03.2015 г.)

12. Проект «Женщина, уверенная в себе» начинает работу в женских исправительных колониях Иркутской области [Электронный ресурc] URL: http://www.38. fsin.su/news/detail.php? ELEMENT_ID=266443 (дата обращения: 12.08 .2017 г.)

13. Синьков Д. В. Преступность женщин: состояние, причины и предупреждение (региональная характеристика): дисс. ... канд. юрид. наук: 12.00.08. Иркутск, 2003. $211 \mathrm{C}$.

14. Соглашение о сотрудничестве между Федеральной службой исполнения наказаний России и Русской Православной Церковыю [Электронный ресурс] URL: http://www.patriarchia.ru/db/text/1414730.html (дата обращения: 12.08 .2017 г.)

15. Уголовно-исполнительный кодекс РФ. М.: Эксмо-Пресс, 2018 г. 160 с.

(c) Кононыхина Татьяна Сергеевна ( tskononykhina@mail.ru).

Журнал «Современная наука: актуальные проблемы теории и практики»

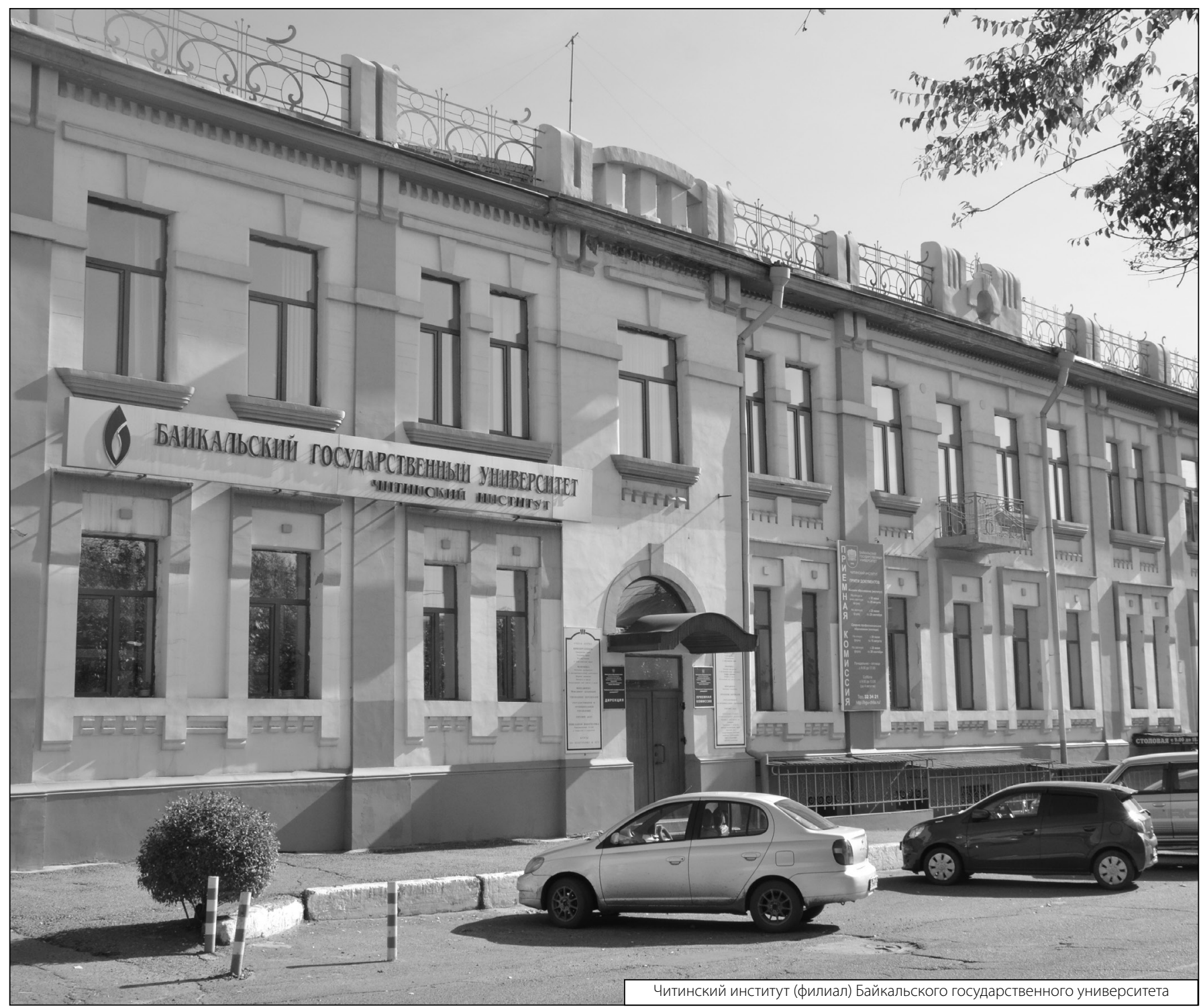

